\title{
SPARC from Olfactory Ensheathing Cells Stimulates Schwann Cells to Promote Neurite Outgrowth and Enhances Spinal Cord Repair
}

\author{
Edmund Au, ${ }^{1}$ Miranda W. Richter, ${ }^{1}$ Adele J. Vincent, ${ }^{1}$ Wolfram Tetzlaff, ${ }^{1,2}$ Ruedi Aebersold, ${ }^{3,4}$ E. Helene Sage, ${ }^{5}$ and \\ A. Jane Roskams ${ }^{1,2}$ \\ 'Department of Zoology, Life Sciences Institute and ${ }^{2}$ International Collaboration on Repair Discoveries, University of British Columbia, Vancouver, British \\ Columbia, Canada V6T 1Z3, ${ }^{3}$ Institute for Systems Biology, Seattle, Washington 98103, ${ }^{4}$ Molecular Systems Biology, Swiss Federal Institute of Technology \\ of Zurich, CH-8092 Zurich, Switzerland, and ${ }^{5}$ Hope Heart Program, Benaroya Research Institute at Virginia Mason, Seattle, Washington 98101
}

Olfactory ensheathing cells (OECs) transplanted into the lesioned CNS can stimulate reportedly different degrees of regeneration, remyelination, and functional recovery, but little is known about the mechanisms OECs may use to stimulate endogenous repair. Here, we used a functional proteomic approach, isotope-coded affinity tagging and mass spectrometry, to identify active components of the OEC secreteome that differentially stimulate outgrowth. SPARC (secreted protein acidic rich in cysteine) (osteonectin) was identified as an OEC-derived matricellular protein that can indirectly enhance the ability of Schwann cells to stimulate dorsal root ganglion outgrowth in vitro. SPARC stimulates Schwann cell-mediated outgrowth by cooperative signal with laminin-1 and transforming growth factor $\beta$. Furthermore, when SPARC-null OECs were transplanted into lesioned rat spinal cord, the absence of OEC-secreted SPARC results in an attenuation of outgrowth of specific subsets of sensory and supraspinal axons and changes the pattern of macrophage infiltration in response to the transplanted cells. These data provide the first evidence for a role for SPARC in modulating different aspects of CNS repair and indicate that SPARC can change the activation state of endogenous Schwann cells, resulting in the promotion of outgrowth in vitro, and in vivo.

Key words: olfactory; regeneration; glia; ICAT; matricellular proteins; spinal cord injury

\section{Introduction}

In the mammalian adult CNS, recovery from injury is generally poor, and axonal regeneration is impeded by secondary inflammation, coupled with an inhibitory environment (Fawcett and Asher, 1999). An exception to this rule is found in the olfactory system, in which olfactory receptor neurons (ORNs) undergo natural and injury-induced turnover and functional neurogenesis throughout life (Graziadei et al., 1979). To accommodate successful adult axon targeting, newly generated ORNs from the peripheral nervous system (PNS) that extend axons to synapse in the olfactory bulb $(\mathrm{OB})$ of the CNS are aided by glia unique to the

Received Feb. 5, 2007; revised April 23, 2007; accepted May 17, 2007.

Funding was provided by Canadian Institutes of Health Research (CIHR) and the Spinal Research Trust (A.J.R.), Multiple Sclerosis Society of Canada (E.A.), Natural Sciences and Engineering Research Council of Canada/Michael Smith Foundation for Health Research (M.W.R.), CIHR (W.T., A.J.R.), National Institutes of Health Grant GM-40711 (E.H.S.), and National Heart, Lung, and Blood Institute under Contract N01-HV-28179 (R.A.). The development of image analysis software (Patrick Fletcher) for this project was supported by the Van Wagener family (Joy to the World Foundation). We thank Patrick Fletcher, Jie Liu, David Dai, and Erin Currie for technical assistance and Jessica MacDonald, Patricia Lau, and other members of the Roskams laboratory for ideas and discussion. Enormous thanks to Sam Donohoe (Institute for Systems Biology, Seattle, WA) for helping to troubleshoot the proteomic and bioinformatics analysis. We also thank David Kaplan and Marie Filbin for their comments on this manuscript.

Correspondence should be addressed to Dr. A. Jane Roskams, Department of Zoology, Life Sciences Institute, University of British Columbia, 2350 Health Sciences Mall, Vancouver, British Columbia, Canada, V6T 1Z3. E-mail: roskams@zoology.ubc.ca.

D01:10.1523/JNEUROSCI.0509-07.2007

Copyright $\odot 2007$ Society for Neuroscience $\quad$ 0270-6474/07/277208-14\$15.00/0 olfactory system, olfactory ensheathing cells (OECs) (RamonCueto and Avila, 1998). Recently, OECs have been transplanted into sites of spinal cord injury and other CNS lesions, with the anticipation that OECs may recreate the plastic environment of the olfactory system elsewhere (Bunge and Pearse, 2003; Fairless and Barnett, 2005).

Several different rat spinal cord injury (SCI) models have indicated that OECs can mediate limited regeneration and functional recovery. However, the degrees of functional and anatomical recovery reported by different laboratories have been quite disparate, ranging from little to extensive functional or anatomical restoration, and there is no demonstrated mechanism of how OECs may directly or indirectly stimulate regeneration or CNS repair (Santos-Benito and Ramon-Cueto, 2003; Riddell et al., 2004). Nevertheless, based on these results, experimental human trials using cells reportedly containing OECs are now ongoing in several countries, with little understanding of whether OECs can faithfully facilitate regeneration (Huang et al., 2003; MackaySim, 2005). We have shown that OECs can be purified and expanded from the lamina propria (LP-OECs) of the olfactory mucosa, the peripheral compartment through which ORN axons pass en route to the OB (Au and Roskams, 2002, 2003). LP-OECs are the first cells to contact outgrowing ORN axons and guide them into the CNS (Doucette, 1990) and are biologically different from those derived from the bulb (OB-OECs) (Richter et al., 
2005). LP-OECs transplanted after SCI can stimulate axon sprouting and invasion of Schwann cells (SCs), minimize glial scar formation, promote directional angiogenesis, and reduce cavity formation (Ramer et al., 2004b; Richter et al., 2005), but the factors responsible for mediating these widespread effects are not known. Regardless of mode of transplantation or lesion model, a clear understanding of how OECs directly modulate the hostile environment of a CNS lesion will allow us to design more effective approaches for promoting neural regeneration and protection but minimize potentially undesirable secondary sprouting (leading to neuropathic pain or autonomic dysreflexia, for example).

Here, we show that serum-free LP-OEC conditioned media (OCM) robustly promotes sensory neurite outgrowth, an activity that diminishes as OECs age in culture. Using a prospective proteomic strategy, isotope-coded affinity tagging (ICAT), to identify candidate outgrowth-promoting factors in OCM, we found that SPARC (secreted protein acidic rich in cysteine) (osteonectin) was present in high levels. SPARC indirectly stimulates neurite outgrowth via a novel mechanism that concurrently facilitates laminin-1 and transforming growth factor $\beta$ (TGF $\beta$ ) signaling to enhance endogenous Schwann cell-mediated outgrowth. Furthermore, SPARC-null (Norose et al., 1998; Bradshaw et al., 2003) LP-OECs transplanted into a rat SCI specifically reduced a normally robust sprouting response of defined sensory and supraspinal axons and also altered the posttransplant immune response. These data suggest that SPARC is a central mediator used by LP-OECs to stimulate endogenous spinal cord repair.

\section{Materials and Methods Animals}

For studies involving SPARC-null mice (provided by E.H.S.), wild-type (WT) age- and sex-matched C57BL/6 mice (The Jackson Laboratory, Bar Harbor, ME) were used as controls. Animal procedures were all performed in accordance with the guidelines of the Canadian Council for Animal Care and the University of British Columbia animal care committee.

\section{Cell culture}

$L P-O E C S$

LP-OECs were generated from outbred CD-1 mice. A detailed protocol can be found in the study of Au and Roskams (2002). Briefly, postnatal day 5 mouse pups were decapitated, and their heads were split midsagittally. The olfactory mucosa and underlying cartilaginous turbinates were dissected out and transferred into DMEM (Invitrogen, Burlington, Ontario, Canada). The tissue was chopped into fine pieces with a razor blade, transferred into a $50 \mathrm{ml}$ conical tube, and spun at $120 \times g$ for 10 min at room temperature. The supernatant was removed, $3 \mathrm{ml}$ of fresh DMEM was added, and the tissue was triturated with a P1000 pipette tip (enlarged by cutting the last $5 \mathrm{~mm}$ off the end). The resulting slurry was spun again at $230 \times g$ for $5 \mathrm{~min}$. A digestion mix containing dispase I (Roche, Baie D'Urfe, Quebec, Canada), collagenase D (Sigma, St. Louis, $\mathrm{MO}$ ), hyaluronidase (Sigma), DNase (Invitrogen), and bovine serum albumin (Sigma) was added to the tissue pellet. The pellet was resuspended and incubated in digestion mix for $60 \mathrm{~min}$ at $37^{\circ} \mathrm{C}$. The tissue was triturated with a serum-coated glass Pasteur pipette and passed through a $40 \mu \mathrm{m}$ nitex filter (Becton Dickinson, Mississauga, Ontario, Canada). The cells were centrifuged at $230 \times g$ for $5 \mathrm{~min}$ and plated in MEM-Dvaline (US Biological, Swampscott, MA) and 10\% fetal bovine serum (FBS). For the next two passages (P), the cells were purified by complement-mediated lysis using an anti-Thyl.1 hybridoma supernatant (American Type Culture Collection, Manassas, VA).

\section{LP-OEC preparation for transplantation}

WT and SPARC-null LP-OECs were retrovirally infected at passage 1 with a retrovirus encoding green fluorescent protein (GFP) (MGIN)
(Hawley et al., 2001), produced by a packaging cell line, PA317 (Miller and Buttimore, 1986). GFP-positive $\left(\mathrm{GFP}^{+}\right)$cells $(\sim 70 \%)$ were selected by fluorescence-activated cell sorting at passage 2 and prepared for transplant at passage 3. Cell suspensions for transplantation were prepared as described previously (Ramer et al., 2004b; Richter et al., 2005). Briefly, WT and SPARC-null LP-OECs were detached with 0.25\% trypsin/ EDTA, resuspended at a concentration of $80,000-90,000$ cells/ $\mu \mathrm{l}$, and immediately transplanted into a recipient rat.

\section{Schwann cells}

Schwann cells for dorsal root ganglion (DRG)-SC coculture were obtained from embryonic day 13.5 (E13.5) DRG explants grown as below and passaged on day in vitro 7 using $0.25 \%$ trypsin and filtered through a $40 \mu \mathrm{m}$ nylon filter. SCs were seeded onto coverslips coated as outlined below and grown for 1-3 d in Neurobasal supplemented with 2\% B27, 20 $\mu \mathrm{g} / \mathrm{ml}$ bovine pituitary extract, and $2 \mu \mathrm{M}$ forskolin. The medium was switched to Neurobasal medium for dissociated DRGs (above) immediately before seeding with neurons at 5000 cell per well.

\section{Lumbar DRG explants}

L2-L4 were dissected from E13.5 embryos as described previously (Banker and Goslin, 1998). The six largest lumbar DRGs were cleaned of spinal and peripheral rootlets and plated onto $15 \mathrm{~mm}$ circular glass coverslips precoated with poly-L-lysine (PLL) $(50 \mu \mathrm{g} / \mathrm{ml}$; Sigma) and laminin-1 (50 ng/ml; Chemicon, Temecula, CA) in 24-well plates with $225 \mu \mathrm{l}$ of media in each well. The media contained DMEM supplemented with $1 \%$ penicillin/streptomycin (Invitrogen), $2 \mathrm{~mm}$ L-glutamine (Sigma), $1.5 \mathrm{~g} /$ liter D-glucose (Sigma), 1\% FBS (Invitrogen), and 1.5 $\mathrm{ng} / \mathrm{ml}$ recombinant human nerve growth factor (NGF) (gift from Regeneron, Tarrytown, NY). Initial experiments determined that $1.5 \mathrm{ng} / \mathrm{ml}$ NGF promoted the survival of similar numbers of cells within the DRG

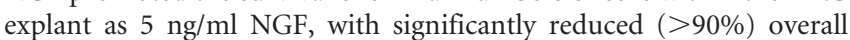
outgrowth.

\section{Lumbar DRGs}

For a pure, dissociated neuronal culture, lumbar DRGs were dissected from E13.5 embryos (as above) and incubated in $0.25 \%$ trypsin plus $0.05 \%$ collagenase for $30 \mathrm{~min}$ at $37^{\circ} \mathrm{C}$ and then mechanically dissociated and purified through $30 \%$ Percoll at $200 \times g$ for $15 \mathrm{~min}$. The neuronenriched pellet was seeded at 5000 cells per well onto coverslips coated with PLL and laminin-1 as above and cultured for $2 \mathrm{~d}$ in Neurobasal (Invitrogen) supplemented with 2\% B27 (Invitrogen), $2 \mathrm{~mm}$ L-glutamine, $1 \%$ penicillin/streptomycin, and $1.5 \mathrm{ng} / \mathrm{ml}$ recombinant human NGF.

\section{Generating conditioned media library}

LP-OECs were cultured as described above. For P2 OCM, primary cultures were plated in MEM-D-valine containing 5\% FBS instead of 10\% FBS and stepped down to $2.5 \%$ FBS $2 \mathrm{~d}$ later. When the cells reached confluency, they were passaged, complement lysed, and replated in $2.5 \%$ FBS. Two days later, the cells were stepped down to $1 \%$ FBS, passaged, complement lysed, and replated in 1\% FBS. Two days later, the cells were switched to serum-free DMEM-Bottenstein-Sato (BS) media (Au and Roskams, 2003) containing the following: DMEM supplemented with $0.5 \mathrm{~nm}$ bovine pancreatic insulin, $100 \mu \mathrm{g} / \mathrm{ml}$ human transferrin, $0.2 \mathrm{nM}$ progesterone, $0.1 \mathrm{~nm}$ putrescine, $0.49 \mathrm{~nm}$ triiodo-L-thyronine, $0.45 \mathrm{~nm}$ L-thyroxine, $0.224 \mathrm{~nm}$ sodium selenite, and $2 \mathrm{~mm}$ L-glutamine (all supplements from Sigma). The cells were grown in DMEM-BS for $96 \mathrm{~h}$ before the removal of conditioned media (see diagram in supplemental Fig. S6, available at www.jneurosci.org as supplemental material). For passage 6 LP-OCM, the serum step-down regimen began at passage 4 when the serum concentration was dropped from 10\% FBS to $5 \%$ FBS $2 \mathrm{~d}$ after plating. LP-OCM was removed from the cells and transferred into $50 \mathrm{ml}$ conical tubes. The tubes were spun at $280 \times g$ for $5 \mathrm{~min}$ at $4^{\circ} \mathrm{C}$ to remove cellular debris. The supernatant was carefully removed and added to an Ultrafiltration Cell (Millipore, Billerica, MA) with a $1 \mathrm{kDa}$ molecular weight cutoff membrane (Millipore). Under 50 psi $\mathrm{N}_{2}$, the conditioned media was forced through the membrane, concentrating the protein constituents $>1 \mathrm{kDa}$. The concentrate was filtered with a 
syringe-driven $0.22 \mu \mathrm{m}$ filter (Millipore) and stored at $-80^{\circ} \mathrm{C}$. Concurrently, the LP-OECs that generated the conditioned media were trypsinized, counted, and stored at $-80^{\circ} \mathrm{C}$. By measuring the volume of the filtrate, the concentration of the media was determined. Each batch of conditioned media was standardized by the number of cells generating 1 $\mathrm{ml}$ of LP-OCM and recorded as its fold concentration after ultrafiltration. In this manner, each batch of conditioned media could be directly cross-compared with the number of cells that produced it. Arbitrarily, full-strength conditioned media was set at 30,000 cells/ml LP-OCM, 1:2 media would then be 15,000 cells/ml LP-OCM, etc.

\section{Neurite outgrowth analysis}

Explants were grown for $48 \mathrm{~h}$ at $37^{\circ} \mathrm{C}$ in $5 \% \mathrm{CO}_{2}$ and subsequently fixed in $4 \%$ paraformaldehyde in PBS for $10 \mathrm{~min}$, washed twice with PBS, and stored in $0.05 \%$ sodium azide (Sigma) in PBS at $4^{\circ} \mathrm{C}$. Baseline media were supplemented with OCM, SPARC (0.1-10 ng/ml), K252a (100 nm; Biosource, Camarillo, CA), PD98059 [2-(2-amino-3-methyoxyphenyl)$4 \mathrm{H}$-1-benzopyran-4-one] mitogen-activated protein kinase (MAPK) inhibitor (100 $\mu \mathrm{M}$; Calbiochem, San Diego CA), and TGF $\beta-1$ (1-100 ng/ $\mathrm{ml}$; R \& D Systems, Minneapolis, MN) to test their effect on neurite outgrowth (see below, Data analysis).

\section{Loss-of-function studies}

For loss-of-function studies, SPARC $(250 \mathrm{ng} / \mathrm{ml}$; generated in the Sage laboratory) and TGF $\beta-1$ (100 ng/ml; R \& D Systems) function-blocking antibodies were added to the medium, which was subsequently incubated on a rocker platform for $1 \mathrm{~h}$ at $4^{\circ} \mathrm{C}$ before use in the neurite outgrowth assay. As controls, TGF $\beta-1$ function-blocking antibody was used under baseline conditions alone, and human-specific SPARC antibody was tested for its ability to block recombinant mouse SPARC (rmSPARC), with mouse-specific antibody tested against human SPARC, using the same preincubation conditions.

\section{Ablation of Schwann cells}

To ablate Schwann cells, we plated explants in media supplemented with $10 \mu \mathrm{M}$ cytosine arabinoside (Sigma) and grown for $48 \mathrm{~h}$. The media was then removed, and the explants were gently rinsed with DMEM to wash off any remaining cytosine arabinoside (AraC). New media was added without $\mathrm{AraC}$, and the explants were grown with or without SPARC (5 $\mathrm{ng} / \mathrm{ml}$ ) for $48 \mathrm{~h}$ before fixation.

\section{Production of recombinant SPARC}

Recombinant human SPARC (rhSPARC) was generated as described previously (Bradshaw et al., 2000). To generate recombinant mouse SPARC, we used the full-length reverse transcription (RT)-PCR product of passage 2 LP-OECs. Restriction sites (HindIII and XhoI, respectively) were added flanking the $\mathrm{N}$ and $\mathrm{C}$ termini. Downstream of the HindIII site, an Ig $\kappa$-chain leader sequence was added to facilitate secretion (Coloma et al., 1992). Downstream of SPARC, a short glycine hinge (CCAC$\mathrm{CAC}$ ) was added to minimize steric hindrance from the epitope tags. The insert was directionally ligated into a pcDNA-V5/His vector (Invitrogen). The vector was transformed into heat-competent $\mathrm{DH} 5 \alpha$ bacteria (Invitrogen) and selected by ampicillin resistance. Clones were selected and sequenced to test for the presence, correct orientation, and reading frame of the insert. DNA from verified clones was purified using a Plasmid Midi kit (Qiagen, Mississauga, Ontario, Canada). Cos-7 cells were transfected using Lipofectamine (Invitrogen) and selected with neomycin for 3 weeks to obtain stable transfectants. Cell lysates and conditioned media were tested for the presence of the V 5 epitope by Western blotting. Cos- 7 conditioned media (concentrated by ultrafiltration) was added to Ni-NTA resin and incubated for $2 \mathrm{~h}$ at $4^{\circ} \mathrm{C}$, washed with low-salt Tris buffer $(200 \mathrm{~mm} \mathrm{NaCl})$ and high-salt Tris buffer $(400 \mathrm{~mm} \mathrm{NaCl})$, and eluted with $300 \mathrm{~mm}$ imidazole in low salt $(100 \mathrm{~mm} \mathrm{NaCl})$. The fractions were assayed for protein content using a BCA kit (Pierce, Rockford, IL), and selected fractions were pooled and dialysed in $10 \%$ glycerol in PBS for $18 \mathrm{~h}$ at $4^{\circ} \mathrm{C}$ to remove Tris. A BCA protein assay was performed after dialysis to quantify the dialysed, sterile-filtered sample.

\section{Surgical procedures}

\section{Bulbectomy}

The unilateral bulbectomy procedure has been described in detail by Roskams et al. (1996). Briefly, an adult CD-1 mouse (8-10 weeks old) was anesthetized with xylaket $(4.5 \mathrm{ml} / \mathrm{kg})$, and a $1.4-\mathrm{mm}$-diameter hole was drilled through the skull directly above the olfactory bulb. The bulb was removed by gentle suctioning. The wound was filled with Gelfoam (Pfizer, New York, NY), and the skin was sealed with VetBond (3M, Minneapolis, MN). Twelve days after the procedure, the mouse olfactory epithelium (OE) and bulb were dissected and processed for sectioning as described previously (Cowan et al., 2001).

\section{Dorsolateral funiculus crush and cell transplantation}

One day before surgery, eight adult male Sprague Dawley rats (140-160 g; Charles River Laboratories, Wilmington, MA) received $20 \mathrm{mg} / \mathrm{kg}$ cyclosporine $\mathrm{A}$ (CsA), with immunosuppression continued throughout the survival period at $10 \mathrm{mg} / \mathrm{kg}$ CsA. Crush of the dorsolateral funiculus was performed as described previously (Ramer et al., 2004a; Richter et al., 2005). In summary, animals were anesthetized with xylazine/ketamine (10 mg/kg, i.p. and $70 \mathrm{mg} / \mathrm{kg}$, i.p.), the left halves of cervical segments 3 and 4 were exposed by performing a hemilaminectomy, the dura was cut with microscissors, and one prong of custom-designed fine surgical forceps was inserted between the gray and white matter to a depth of $1 \mathrm{~mm}$. With the other prong outside the dorsolateral funiculus, the forceps were closed for $20 \mathrm{~s}$, crushing the dorsolateral funiculus. The reproducibility of this injury has been verified previously by our laboratory (Richter et al., 2005).

Rats were designated to transplant groups (SPARC null, $n=4$; WT, $n=4$ ) after spinal cord injury. Each rat was stereotaxically transplanted with 120,000-135,000 WT or SPARC-null LP-OECs suspended in DMEM/F-12 drawn into a 30-40 $\mu$ m pulled glass pipette in a Hamilton syringe. Injection sites were all within the lesion site at depths of $0.7,1.0$, and $1.5 \mathrm{~mm}$, with each site receiving $0.5 \mu \mathrm{l}$ of cell suspension. The glass pipette remained in place for $5 \mathrm{~min}$ and was slowly withdrawn to ensure that cells remained in the spinal cord. The muscle and skin were closed with interrupted sutures, and all animals survived for $28 \mathrm{~d}$ after transplantation. Transplantation was performed independent of analysis, all animals were coded, and investigators were blinded for analysis.

\section{Immunocytochemistry and immunohistochemistry}

\section{Immunocytochemistry}

Procedures for tissue fixing and preparation for histochemistry have been described previously (Cowan et al., 2001). Four percent paraformaldehyde-fixed coronal sections of $\mathrm{OE}$ and $\mathrm{OB}$ were permeabilized in $0.1 \%$ Triton X-100 (Sigma) in PBS for 30 min and then blocked in $4 \%$ normal serum in PBS for $20 \mathrm{~min}$. The tissue was next incubated with primary antibody in $2 \%$ normal serum in PBS at $4^{\circ} \mathrm{C}$ for $12-16 \mathrm{~h}$. Antibodies were detected by indirect immunofluorescence with Alexa fluorescent secondary antibodies (Invitrogen, Carlsbad, CA). To process DRG explants for neurite outgrowth quantification, we modified the immunohistochemistry procedure such that the coverslips were gently transferred upside down on $80 \mu \mathrm{l}$ droplets to minimize physical disruption of the delicate neurite carpet. Primary antibodies used for immunohistochemistry were as follows: rabbit anti-neurofilament heavy chain (1:500; Serotec, Raleigh, NC); goat anti-SPARC (1:1000; R \& D Systems); mouse anti-S100 $\beta$ (1:500; Sigma); rabbit anti-neural cell adhesion molecule (NCAM) (1:500; Chemicon); rabbit anti-laminin (1:500; Serotec); rabbit anti-P200 type V collagen (gift from Dr. David Carey, Weis Centre for Research, Geisinger Clinic, Danville, PA); rabbit anti-mouse p75 (1: 500; Chemicon); and mouse anti-neuron-specific tubulin, TUJ1 clone (1:500; Covance, Princeton, NJ).

Schwann cells were visualized using 4', $6^{\prime}$-diamidino-2-phenylindole (DAPI) (Sigma) to label their nuclei, and the percentage of Schwann cells was verified by testing the number of DAPI-positive cells that were coexpressing $S 100 \beta$ and the P200 collagen isoform (Chernousov et al., 1999, 2000). The number (excluding the ganglion) of DAPI-positive nuclei underlying the neurite carpet was counted by use of Northern Eclipse (Empix Imaging, Mississauga, Ontario, Canada). 
Immunohistochemistry

Animals transplanted with SPARC-null and WT LP-OECs were killed by lethal overdose of chloral hydrate $(100 \mathrm{mg} / \mathrm{kg}$, i.p.) and transcardially perfused with PBS followed by $4 \%$ paraformaldehyde, and the spinal cords were cryoprotected by successive treatment with 12,18 , and $24 \%$ sucrose in PBS. Spinal cords frozen in isopentane over dry ice were cut transversely at $14 \mu \mathrm{m}$, collected on superfrost plus slides, and immunoreacted using standard immunohistochemical procedures described previously (Richter et al., 2005). The following primary antibodies were used: rabbit anti-calcitonin gene-related peptide (CGRP) (1:500; Sigma), mouse anti-rat CD68 (ED1, 1:500; Serotec), rabbit anti-glial fibrillary acidic protein (GFAP) (1:400; DakoCytomation, High Wycombe, UK), rabbit anti-laminin (1:1000; Sigma), rabbit anti-neurofilament heavy chain (1:500; Serotec), mouse anti-rat p75 (1:1000; Chemicon), mouse anti-rat endothelial cell antigen 1 (1:50; Serotec), rabbit anti-serotonin (5-HT) (1:8000; Immunostar, Hudson, WI), goat anti-mouse SPARC (1:500; R \& D Systems), rabbit anti-substance P (1:1000; Chemicon), and rabbit anti-tyrosine hydroxylase (1:250; Chemicon). Secondary antibodies raised in goat and conjugated to Alexa 350, 488, or 594 were applied, and sections were coverslipped in Vectashield (Vector Laboratories, Burlingame, CA).

\section{Western blotting}

SDS-PAGE protein gels were performed according to standard procedures (Cowan and Roskams, 2004). To prepare samples for Western blotting, LP-OCM was loaded at a volume equivalent to 50,000 cellsworth of media. (0.25\% trypsin and 1\% EDTA), washed with PBS, lysed (50 mm Tris- $\mathrm{HCl}, \mathrm{pH} 7.5,150 \mathrm{~mm} \mathrm{NaCl}, 1 \% \mathrm{NP}-40 \mathrm{w} / \mathrm{v}$, and $5 \mathrm{~mm}$ EDTA), and loaded at $25 \mu \mathrm{g} / \mathrm{lane}$. Goat anti-SPARC was diluted 1:1250, mouse anti- $\beta$-tubulin was diluted 1:2500, and secondary antibodies were diluted at 1:5000. For quantification of relative amounts of SPARC, blots were analyzed by densitometry $(n=3)$.

\section{Data analysis \\ Image capture}

Fixed explants were processed for immunofluorescence analysis using neurofilament heavy chain antibody, as described below. $Z$-stacked images (at $200 \times$ magnification, $0.1 \mu \mathrm{m}$ per step) of the explant were captured using an Axioplan2 Imaging fluorescent microscope (Zeiss, Jena, Germany) and reassembled using Northern Eclipse 6.0 imaging software (Empix Imaging). The entire explant was canvassed in this manner and was pieced together as separate layers using Photoshop 7.0 (Adobe Systems, San Jose, CA).

\section{Quantification of explant outgrowth}

We primarily used two methods to quantify explant outgrowth: skeletonization and average neurite carpet radius (for more detail on neurite carpet surface area and total neurite signal, see supplemental data, available at www.jneurosci.org as supplemental material).

Skeletonization. Skeletonization measures total neurite length by processing DRG montages with Northern Eclipse running the macro "Neurobinary." Neurobinary reduces the image, originally an eight-bit grayscale image, to a purely black and white image after user-specified thresholding. The ganglion is omitted from analysis and the image is skeletonized by comparison of each pixel to its eight neighbors, eliminating them one by one until the signal is reduced to one pixel width. All signals $>25$ pixels in size are counted such that the number of pixels correlates with the total neurite outgrowth.

Average neurite carpet radius. To quantify average neurite carpet radius, DRG montages were processed using Northern Eclipse running the macro "Neuroquant." In Neuroquant, the user defines the center of the ganglion and then outlines the outer edge of the explant. A series of equidistant points are laid along the outline, and the computer measures the distance from the center of the ganglion to each of the points. The distances are averaged to produce an average outer radius (R1) (supplemental Fig. S1 $B$, available at www.jneurosci.org as supplemental material). A similar analysis is performed outlining the ganglion itself to give the inner radius (R2) (supplemental Fig. S1 B, available at www.jneurosci.org as supplemental material). $\mathrm{R} 2$ is subtracted from $\mathrm{R} 1$ to give the average axon radius.

Assessment of differences in fasciculation. To assess differences in fasciculation of neurites between conditions, raw explant montages were first processed using a local thresholding and filtering algorithm based on the Wiener filter (Matlab; MathWorks, Natick, MA). The largest connected component was then selected using the Matlab image processing toolbox. This area, corresponding to the entire neurite carpet, was quantified by counting the total number of lit pixels. Because information concerning neurite width, which corresponds to increases in the number of neurites traveling together, is lost by skeletonizing the explant, a ratio of the entire processed but unskeletonized neurite carpet to the skeletonized carpet provides a measure of fasciculation.

\section{Statistical analysis}

Five hundred seventeen DRG explants were analyzed to obtain the data included in this manuscript. Each experimental condition had between four and six explants per $n$, with a minimum of $n=3$ for each experimental condition. Outgrowth measurements for each experimental condition were pooled and averaged, and the SD was determined. Error bars are reported as SEM $(\mathrm{SD} / \mathrm{V} \mathrm{n})$. Two-tailed ANOVA was performed on the raw pooled data, and statistical significance was determined by a two-tailed Student's $t$ test or Newman-Keuls test for multiple group comparisons.

\section{Image analysis and quantification of transplants}

Sections at the lesion epicenter as well as $98 \mu \mathrm{m}$ apart above and below the lesion site were immunoreacted, and $Z$-stacked $200 \times$ or $100 \times$ montaged digital images were captured with an Axioplan 2 microscope (Zeiss), a digital camera (QImaging, Burnaby, British Columbia, Columbia), and Northern Eclipse software (Empix Imaging). Images were processed using Northern Eclipse (Empix Imaging) and Photoshop 7 (Adobe Systems). Quantification of axon sprouting was performed as described previously (Richter et al., 2005) by binning fluorescence from axon staining into four bins, removing autofluorescent items, and counting fluorescent pixels in the top three bins in a defined area of 750,000 pixels centered at the rostral/caudal lesion border and $0.5 \mathrm{~mm}$ rostral/ caudal from the GFAP-immunoreactive border. Quantification of positive pixels within the lesion site was performed as above; however, the lesion site was defined by outlining a selection area at the GFAPimmunopositive lesion boundary. Quantification of ED1-positive macrophages was performed similarly by outlining the GFAPimmunoreactive border and counting the number of positive cells (that also contained a DAPI ${ }^{+}$nucleus) within, and at successive intervals away from, the lesion site. ANOVA and Newman-Keuls testing were used to compare across groups for axon quantification; $t$ tests were used to compare groups for ED1-positive cell counts.

\section{Results}

\section{Selection of a neurite outgrowth assay}

OB-OECs can promote neurite outgrowth in coculture with ORNs (Chuah and Au, 1994; Kafitz and Greer, 1999), retinal ganglion cells (Sonigra et al., 1996), and sensory and sympathetic neurons (Lipson et al., 2003). We previously demonstrated significant sensory axon sprouting in response to transplanted LPOECs in vivo, a response that may require tight regulation to maximize desired and minimize undesired regeneration (that may lead to neuropathic pain) after lesion (Ramer et al., 2004b; Richter et al., 2005). OEC activity is attributed, in part, to secreted factors (Kafitz and Greer, 1999; Chung et al., 2004). Here, we selected a well established model of sensory outgrowth and guidance E13.5 mouse DRG explants, to elucidate the mechanisms whereby LP-OECs promote neurite outgrowth. These explants contain a mixed population of DRG-associated cells, similar to that found in vivo. At E13.5 (mouse) to E15 (rat), DRGs are primarily dependent on NGF chiefly for survival (Ruit et al., 1992; Mu et al., 1993), yield the greatest reproducibility and sen- 
Table 1. Statistical comparisons of P2 OCM-induced outgrowth analyses

\begin{tabular}{lll}
\hline Quantitation method & $f^{2}$ value & $p$ value \\
\hline Neurite signal & 13.7412699 & 0.00048671 \\
Skeletonization & 15.1524383 & 0.00031959 \\
Carpet surface area & 3.34998808 & 0.0274756 \\
Average neurite radius & 3.08719892 & 0.03661897 \\
\hline
\end{tabular}

sitivity in a high-throughput assay, and are also the focus of an extensive literature with which to directly compare our findings.

\section{OECs promote DRG neurite outgrowth}

Four methods of quantification were cross-compared (for more detail, see supplemental Fig. S1, available at www.jneurosci.org as supplemental material): (1) skeletonization, (2) average neurite carpet radius, (3) surface area of neurite carpet, and (4) total signal of neurite carpet. Although each approach generated a different output, we wanted to assay the total amount of neurite produced (independent of neurite diameter). Total neurite carpet signal and skeletonization were found to be the most sensitive and least variable methods, as determined by comparing their $p$ values and $f^{2}$ scores on ANOVA (Table 1 ). This approach reduces all neurites (small and large diameter, or fasciculated) to one pixel width, rendering a total pixel count that represents total neurite length (see Materials and Methods). A baseline NGF concentration $(1.5 \mathrm{ng} / \mathrm{ml})$ was determined at which the DRG neurons within explants consistently survived with similar frequency to the survival index recorded at higher concentrations (up to 5 $\mathrm{ng} / \mathrm{ml}$ ) but with minimal neurite outgrowth (Fig. $1 A$ ).

DRGs, plated on LP-OEC monolayers, substantially and significantly increased neurite outgrowth (Fig. $1 B$ ) as measured by skeletonization of total outgrowth (Fig. $1 I$ ). To test whether this outgrowth could be attributed to LP-OEC secreted factors, we generated a stepwise approach to grow LP-OECs in serum-free media that was collected after $5 \mathrm{~d}$, concentrated by ultrafiltration, and frozen before assay. OCM applied to DRGs (Fig. $1 C, D)$ stimulated a significant increase in total outgrowth over NGF alone (Fig. 1A), with P2 OCM (Fig. 1C) more effective than P6 OCM (Fig. 1D). Similar degrees of enhanced outgrowth (in which P2 OCM $>$ P6 OCM) of both large- and small-caliber processes were found in postnatal day 5 DRG explants that already represent more mature sensory modality (CGRP, parvalbumin, and substance $\mathrm{P}$ ) phenotypes (data not shown). By skeletonization analysis, OCM and LP-OEC coculture appeared to evoke similar degrees of DRG outgrowth (Fig. 1I), but the length of outgrowth and the pattern of branching and fasciculation of neurites appeared to differ significantly (Fig. $1 B, C$, insets). To address differences in outgrowth pattern attributable to fasciculation (coculture) versus increased neurite branching/neurite density (P2 OCM), we generated an algorithm that would allow us to directly evaluate the raw total outgrowth (total amount of neurite) compared with skeletonized outgrowth (the most conservative outgrowth assessment). Raw images of all channels (Fig. $1 E$ ) were first processed to remove fluorescent interference from the underlying cellular layer (Fig. $1 F$ ). This processed image (Fig. $1 F$ ) was used to assess the number of pixels representing raw heavychain neurofilament 200 expression, yielding a value for total outgrowth, and a scale of intensity from blue (representing single neurites) to heavily fasciculated (white). When the values obtained from the skeletonized image were subtracted from total pixels (Fig. 1G), the resulting difference between raw and skeletonized images (Fig. $1 \mathrm{H}$ ) was significantly greater for coculture versus P2 OCM, indicating that neurites are not only longer but significantly more fasciculated in LP OEC coculture than in P2 OCM $(p \leq 0.05)$ (Fig. $1 J)$.

Many OEC transplant studies have produced conflicting data regarding the ability of OECs to promote regeneration, even in the same model of SCI (Ramon-Cueto and Nieto-Sampedro, 1994; Ramer et al., 2004a; Riddell et al., 2004). Some of these differences may be attributable to different culture conditions that could change the biology of OECs and how they behave after transplantation (Franklin et al., 1996; Li et al., 1997; RamonCueto et al., 1998; Ramer et al., 2004b). For example, LP-OECs reproducibly senesce with time in culture and successive passaging, with a marked decrease in survival and proliferation by passage 6 in vitro (Au and Roskams, 2003) and after acute transplantation in vivo (M. Richter and A. J. Roskams, unpublished data). To test whether senescence also adversely affects how OECs stimulate neurite outgrowth, we directly compared OCM from P2 and P6 LP-OECs purified from the same tissue source and found that P2 OCM was significantly more effective than P6 OCM in promoting outgrowth (Fig. $1 C, D, K$ ). At lower concentrations of OCM, the difference in outgrowth activity of P2 and P6 LP-OCM was even more pronounced. Heat-denaturing P2 OCM resulted in total loss of outgrowth activity, indicating that the active factor(s) in P2 OCM are likely proteins (data not shown). These findings indicate that proteins secreted by LP-OECs promote DRG neurite outgrowth and suggests significant changes in the quality or quantity of stimulatory or inhibitory secreted proteins as a result of senescence.

\section{ICAT analysis of OEC-conditioned media}

To identify factors that are differentially represented in P2 and P6 OCM, we applied a differential proteomic assay ICAT labeling followed by mass spectrometry analysis, which has been highly effective for analysis in relatively simple systems (Gygi et al., 1999). In this method, two samples are differentially labeled on cysteine residues with isotopically coded reagents and digested with trypsin. Tandem mass spectroscopy of the generated peptides provides the information to allow us to bioinformatically identify and quantify the constituent proteins (Fig. 2A) (Von Haller et al., 2003). The quantitative aspects of ICAT are well suited to analyzing P2 versus P6 OCM, because differences between the samples are more likely attributable to changes in protein quantity than absolute changes in identity. As well, $96 \%$ of the human proteome contains at least one cysteine residue (Cagney et al., 2003), and we first determined (bioinformatically) that $>90 \%$ of known peptide growth factors contain sufficient cysteine residues that, if found in OCM, could be prospectively labeled with the ICAT reagent (Gygi et al., 1999). This gave us the confidence that we should be able to identify the majority of proteins with neurotrophic activity in OCM. In addition, transferrin (added as a supplement to the serum-free media) contains several cysteines and served as an internal positive control between separate ICAT proteomic analyses of LP-OCM for digestion and labeling. Although each individual assay $(n=3$, independent samples and assays) consistently produced $>50$ candidates that were more highly represented in P2 versus P6 OCM, only those that consistently were at least $25 \%$ greater in three assays are reported here.

The ICAT dataset reported that P2 OCM was superior to P6 OCM in the differential presence of (1) selected growth factors, such as pigment epithelium-derived factor and vascular endothelial growth factor; (2) proteins that can regulate growth factor or extracellular matrix (ECM) activity, such as insulin-like growth 

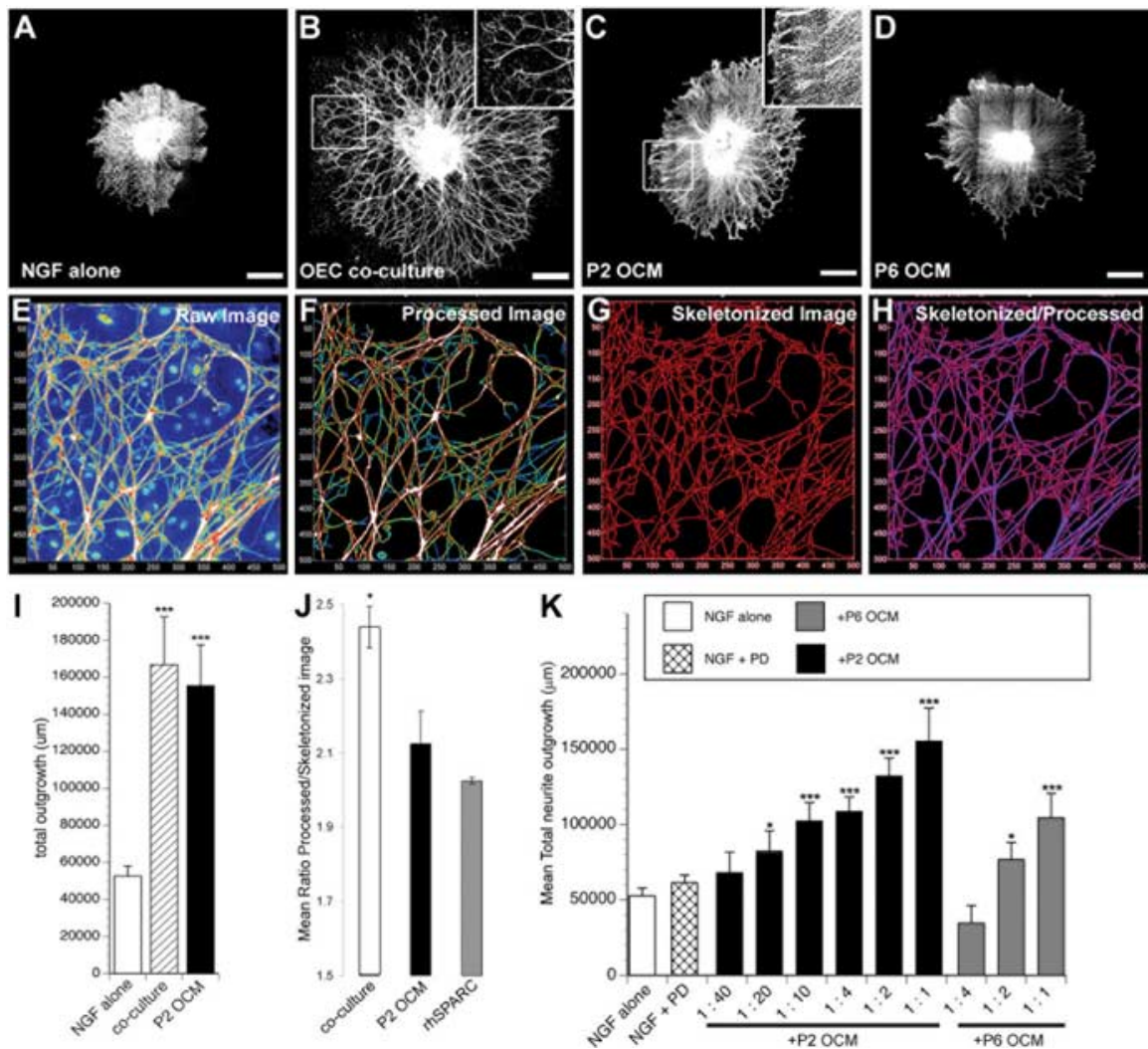

Figure 1. Olfactory ensheathing cells promote neurite outgrowth. $\boldsymbol{A}-\boldsymbol{D}$, Representative montages of embryonic $D$ RG explants grown in the presence of NGF alone $(\boldsymbol{A})$ or NGF cocultured on OEC monolayer $(\boldsymbol{B})$ or supplemented with passage $20 \mathrm{EC}$-conditioned media (P2 OCM) $(\boldsymbol{C})$ or passage $60 C M(D)$. $\boldsymbol{E}$, To quantify total neurite length for explants grown in NGF alone or supplemented with an $0 \mathrm{EC}$ monolayer or P2 $0 \mathrm{CM}$, images were filtered $(\boldsymbol{F})$ and skeletonized $(\boldsymbol{G})$, and total pixels for each condition were counted (I). J, Qualitative differences in outgrowth (fasciculation) were measured as the ratio of filtered to skeletonized outgrowth $(\boldsymbol{H}) . \boldsymbol{K}$, Total neurite length quantified for explants grown in NGF supplemented with the MAPK inhibitor PD98059 (PD) or passage 2 (P2 $0 \mathrm{CM}$ ) or passage 6 (P6 0CM) at various concentrations. ${ }^{*} p<0.05$; ${ }^{* * *} p<0.0005$. Scale bars, $500 \mu \mathrm{m}$.

factor binding proteins 2 and 4, latent TGF $\beta$ binding protein (LTBP), and fibrillin; (3) ECM components (laminin-1, collagens $\mathrm{I} \alpha 2$, III, $\mathrm{V} \alpha 2$, and IVm X1 $\alpha 1, \alpha 2$ heparan sulfate glycoprotein, and fibronectin); and (4) matrix metalloprotease 9 and tissue inhibitor of metalloprotease 2. One factor in particular, SPARC, drew our attention because of its elevated expression in $\mathrm{P} 2$ versus $\mathrm{P} 6 \mathrm{OCM}(30-50 \%$ greater; $n=3)$, its strong and consistent representation in all ICAT analyses performed, and its reported contribution to bone remodeling and wound repair. SPARC is a matricellular protein belonging to a functional family that includes thrombospondin 1 and 2 and tenascin $\mathrm{C}$, all of which can modulate cellular and axonal interactions with ECM molecules (Brekken and Sage, 2001). Domain analysis of SPARC suggests that it could modify both the matrix and growth factor environment of a lesion, although it has not been implicated previously in CNS repair. SPARC can modulate the activity of several growth factors, including platelet-derived growth factor (Raines et al., 1992) and TGF $\beta$ (Reed et al., 1994; Francki et al., 1999; Barker et al., 2005).

\section{SPARC is dynamically expressed in OECs}

To confirm the differential expression of SPARC in P2 and P6 OCM reported in ICAT, we tested purified LP-OECs by RT-PCR (supplemental Fig. S2, available at www.jneurosci.org as supplemental material), Western blotting (Fig. $2 B, C$ ), and immunohis- tochemistry (Fig. 2D-I). P2 OCM contained $33 \pm 8 \%$ more SPARC than $\mathrm{P} 6$ OCM as determined by Western blot densitometry, consistent with the ICAT results (Fig. $2 B$ ) (data not shown). As in the neurite outgrowth assay, LP-OCM sample loading was normalized to the number of LP-OECs that generated the media. In contrast, Western blot analysis of cell lysates from P6 and P2 LP-OECs indicated that P6 OECs contain more intracellular SPARC than P2 LP-OECs (Fig. 2C). SPARC was primarily localized to vesiclelike structures, apparently part of the trans-Golgi network (Fig. 2D).

LP-OECs are either tightly associated with axon bundles in vivo or course through the LP, between axon bundles and up to the basal lamina (Doucette, 1990). In the postnatal day 5 nasal mucosa (the time point at which primary cultures were derived), SPARC is highly expressed by cells in the cartilaginous nasal septum, consistent with its role in chondrocyte development (Sage et al., 1989), and appears most highly expressed by LP-OECs that are in close contact to, and directly ensheathing, neurons (Fig. 2E,F). SPARC distribution in the lamina propria coincides with laminin (Fig. $2 F$ ), indicating that SPARC is ideally placed to interact with and regulate the activity of laminin-1, as it can in other tissues (Rempel et al., 2001; Sweetwyne et al., 2004; Yan et al., 2005). LP-OEC expression of SPARC declines in adult LP OECs, which might reflect a shift in OEC state to preferentially stabilize mature axons because, in the adult OE, there is a lower frequency of axon growth (Farbman, 1990). We reasoned that, if LP-OEC secreted SPARC mediates new axon outgrowth in the adult olfactory system, its expression should increase when ORNs regenerate after lesion. To test this, we unilaterally ablated the OB, axotomizing all mature ORNs distally (Graziadei and Monti Graziadei, 1983), and inducing neurogenesis of newly generated ORNs in the olfactory epithelium that extend axons toward the OB (Cowan et al., 2001). An upregulation in SPARC expression by OECs at $12 \mathrm{~d}$ after bulbectomy is confined to the lesioned $\mathrm{OE}$ (Fig. $2 H, I$ ), coincident with robust ORN axon growth from newly formed ORNs (Roskams et al., 1996; Struble et al., 2001). These data not only confirm that OECs synthesize SPARC in vivo but also indicate that SPARC is dynamically regulated during outgrowth in the olfactory system.

\section{Functional validation of SPARC}

To directly test whether SPARC is a major constituent of the outgrowth-promoting activity of OCM, we cross-tested the neurite outgrowth-promoting activity of recombinant mouse SPARC (epitope-tagged rmSPARC) and rhSPARC on DRG neurite outgrowth. Both mouse and human SPARC robustly promoted outgrowth in a concentration-dependent manner (Fig. $3 A$ ). In all subsequent experiments, rhSPARC was preferentially used ( $5 \mathrm{ng} / \mathrm{ml}$ ) because (1) it exhibited similar outgrowth activity to rmSPARC and (2) it was highly purified (>95\%), so we could 
directly compare its bioactivity in our outgrowth assays with its activity in other assays (Bradshaw et al., 2000; Sweetwyne et al., 2004; Wang et al., 2005; Yan et al., 2005). We next tested whether the outgrowth promoting-activity of SPARC could be inhibited using functionblocking antibodies specific to both mouse and human SPARC. Despite 90\% identity between mouse and human SPARC, Ab255 binds to and specifically blocks mouse SPARC, and Ab236 is specific for human SPARC (Sweetwyne et al., 2004). Both function-blocking antibodies significantly and specifically reduced the outgrowth-promoting activity of their respective SPARC homologs (Fig. 3B). To test the contribution of SPARC to the overall bioactivity of OCM, we used Ab255 against full-strength (1:1) P2 and P6 OCM and substantially reduced the outgrowth activity of OCM, although the decrease was less pronounced (but still significant) with P6 OCM (Fig. 3C). Neither antibody cross-reacted with SPARC from the alternate species, nor did they independently affect outgrowth in the presence of NGF alone (data not shown).

To determine whether other factors in OCM may stimulate outgrowth independently of SPARC, we prepared LP-OECs from SPARC-null mice (Bradshaw et al., 2003), from which we generated P2 SPARC-null OCM. A decrease in outgrowth activity was observed with $\mathrm{P} 2$ SPARC-null OCM, but its outgrowth activity was still significantly greater than that of NGF alone ( $p=0.00272)$, indicating that other factors in OCM could stimulate outgrowth and/or that P2 SPARC-null LPOECs might alter the synthesis of other factors to compensate for the loss of SPARC (Fig. 3C). Interestingly, the average neurite carpet radius was similar between P2 wild-type and P2 null OCM conditions (Fig. 3D,E) (supplemental Fig. S3, available at www. jneurosci.org as supplemental material), but a marked decrease in neurite density was observed in P2 SPARC-null OCM-treated explants (Fig. 3D,E). These complementation and loss-offunction studies indicate that SPARC is a major, but not sole, contributor to the outgrowth activity of OCM in vitro.

\section{Mechanism of SPARC action}

Having established that SPARC regulates sensory neurite outgrowth, we next dissected its mode of action. Our previous work and that of others have suggested that OECs might indirectly stimulate endogenous glia (both astrocytes and Schwann cells) to assist in regeneration or repair. In this study, we originally selected to work with explants instead of dissociated neurons, because they more closely represented the "in vivo" situation of axons in contact with endogenous glia that LP-OECs may encounter in a transplant environment. However, the complexity of an explant also allowed for the potential for our outgrowth readout to be the result of an indirect effect of OCM-derived factors on neurite-associated cells. In OCM-stimulated explants, we established that $87.9 \pm 1.8 \%$ of the cells underlying the neurite
S100B SPARC

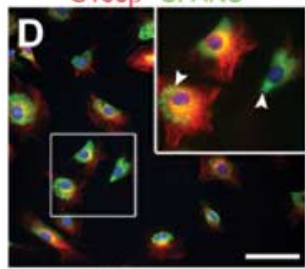

NCAM SPARC

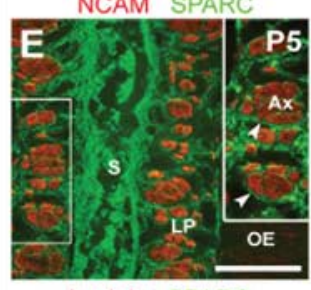

laminin SPARC

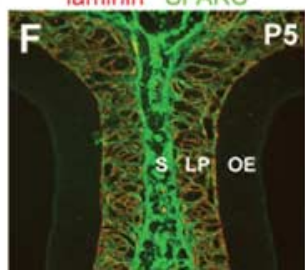

NCAM SPARC

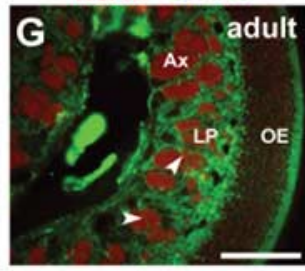

NCAM SPARC

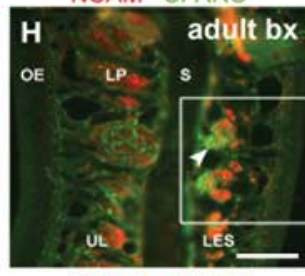

NCAM SPARC

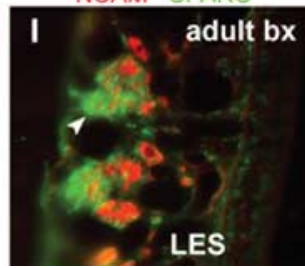

Figure 2. Expression of SPARC by OECs in vitro and in vivo. $\boldsymbol{A}$, Experimental approach for identifying candidate proteins from OEC-conditioned media. Passage 2 and passage 6 OCM are differentially labeled and processed for ICAT proteomic analysis. Candidate factors are identified from the ICAT dataset by correlating a priori data, relative quantity, and biological activity.

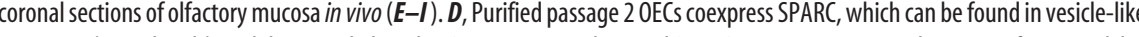
(arrowheads) and is upregulated in response to a unilateral bulbectomy lesion (arrowheads) $(\boldsymbol{H}, \boldsymbol{I} \boldsymbol{I} \boldsymbol{I}$ is higher magnification of box in $\boldsymbol{H}$ ). S, Nasal septum; LP, lamina propria; Ax, axon bundle; P5, postnatal day 5; Bx, bulbectomy; UL, unlesioned;

carpet were SCs (assayed by double-positive $\mathrm{S} 100 \beta^{+} / \mathrm{P} 200^{+}$antigenicity) and appeared to tightly align along neurites (Fig. $3 D, E)$ in the presence of SPARC.

Because our data thus far do not distinguish whether SPARC stimulates outgrowth by acting directly on DRG neurites or via an indirect mechanism that requires SCs, we labeled nuclei in the neurite carpet with DAPI to test whether the density or distribution of SCs was directly affected by the presence of SPARC. There was a significantly decreased density of dispersed SCs in SPARCsupplemented explants $\left(431 \pm 16\right.$ nuclei/ $\left./ \mathrm{mm}^{2}\right)$ versus NGF alone (536 \pm 45 nuclei $/ \mathrm{mm}^{2}$ ) (Fig. $4 A-C$ ). Furthermore, despite the reduction in explant-derived SCs detected in the presence of SPARC, the outgrowth stimulated per SC in the neurite carpet exhibited a highly significant twofold increase in outgrowth from $59.35 \pm 11.3 \mu \mathrm{m} / \mathrm{SC}$ in NGF control explants to $117.25 \pm 9.6$ $\mu \mathrm{m} / \mathrm{SC}$ when $5 \mathrm{ng} / \mathrm{ml} \mathrm{rhSPARC}$ was included. Overall, the ratio of total outgrowth per SC nucleus (in all conditions tested) increased significantly with explants grown in SPARC.

Because these results indicate a relationship between SC state and outgrowth promotion, we next added AraC immediately on plating for $2 \mathrm{~d}$ (which reproducibly eliminated $82-85 \%$ of SCs). By then performing an outgrowth assay for an additional $2 \mathrm{~d}$ with or without SPARC, we were able to test whether removing the majority of SCs attenuated the outgrowth-promoting effects of SPARC. When SCs were essentially eradicated from the neurite carpet, outgrowth recorded from the SPARC and (low) NGF 


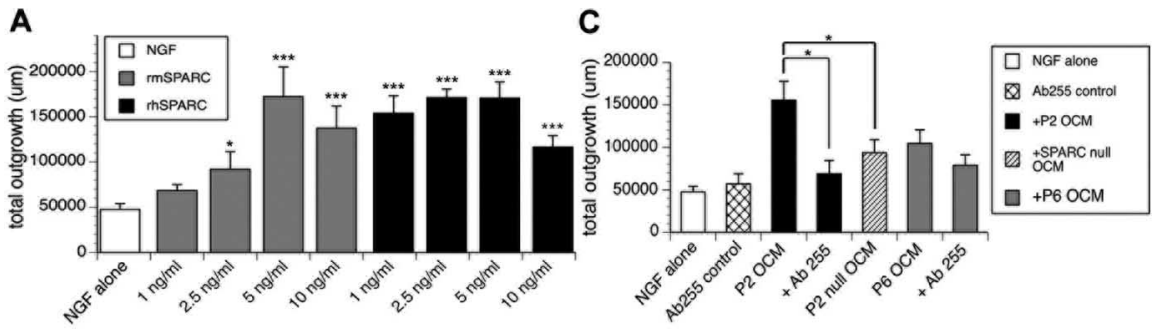

B
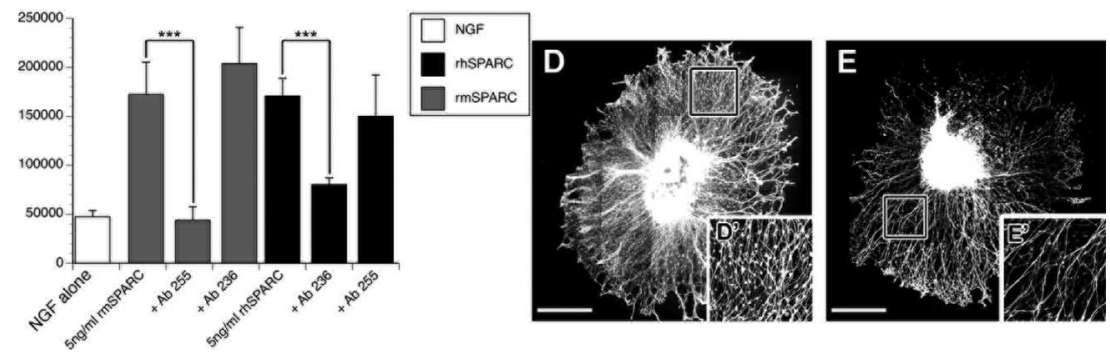

Figure 3. Functional validation of SPARC. $A$, Total neurite length quantified for explants grown in NGF alone or supplemented with rmSPARC or rhSPARC at various concentrations. $\boldsymbol{B}$, Mouse-specific (Ab255) and human-specific (Ab236) SPARC functionblocking antibodies inhibit the neurite outgrowth activity of rmSPARC and rhSPARC, respectively. C, Ab255 function-blocking antibody inhibits the outgrowth activity of P2 OCM and P60CM. Passage 2 conditioned media from SPARC-null OECS (P2 Null OCM) exhibits reduced neurite outgrowth activity compared with wild-type P2 OCM. $D, E$, Representative montages of DRG explants grown in NGF supplemented with wild-type P20CM (D) or SPARC-null P2 OCM (E). $\boldsymbol{D}^{\prime}, \boldsymbol{E}^{\prime}$, Insets are higher magnification of boxes in $\boldsymbol{D}$ and $\boldsymbol{E}$, respectively. ${ }^{*} p<0.05 ;{ }^{* * *} p<0.0005$. Scale bars, $100 \mu \mathrm{m}$.

control groups was indistinguishable (Fig. $4 J$ ), suggesting that SCs may be necessary for the outgrowth-promoting activity of SPARC. SPARC can function cooperatively with different ECM components (Brekken and Sage, 2001). Because laminin-1 and other ECM components are also highly represented in P2/P6 OCM and SPARC expression in the olfactory system overlaps with laminin-1 (Fig. $2 F$ ), we also tested whether laminin-1 was required for SPARC outgrowth promotion and concomitant changes in SC mitosis. When laminin-1 was excluded from the explant substrate, SPARC-induced neurite outgrowth was significantly reduced, although baseline initial outgrowth in NGF controls were unaffected (Fig. $4 \mathrm{~J}$ ). This indicates that SPARC can act cooperatively with laminin-1 to enhance neurite outgrowth. SPARC did, however, stimulate outgrowth to a minor degree, without exogenous laminin-1 in the substrate, which can potentially be accounted for by the synthesis of endogenous laminin-1 by Schwann cells.

Overall distance of migration of SCs from the edge of the explant to the edge of the neurite carpet was not changed significantly in the presence of SPARC (data not shown). However, parallel Boyden chamber migration assays indicated that, in a $24 \mathrm{~h}$ assay, unprocessed recombinant human SPARC $(5 \mathrm{ng} / \mathrm{ml})$ directly and significantly inhibits both the mitosis and the migration of purified SCs on laminin-1 (supplemental Fig. S5, available at www.jneurosci.org as supplemental material) while concurrently increasing the number of Schwann cells by $1.76 \pm 0.11$ fold over Schwann cells in baseline media containing 1\% FBS (in DMEM). This result suggests that SPARC, although decreasing the mitosis and autonomous migration of SCs, might simultaneously shift them to an enhanced outgrowth-promoting phenotype and that SPARC acts indirectly via SCs, not directly on DRG neurites.

To further test whether SPARC can directly stimulate neurite outgrowth, DRG neurons were grown in pure, dissociated culture for $2 \mathrm{~d}$ in the presence or absence of SPARC, in low NGF on a laminin-1/poly-L-lysine substrate (Fig. 4D, G). DRG neurons did not adhere and survive when laminin-1 was excluded from the plating substrate. SPARC did not stimulate neurite outgrowth at any concentration between 1 and $50 \mathrm{ng} / \mathrm{ml}(5 \mathrm{ng} / \mathrm{ml}$ shown in Fig. $4 K$ ). To test whether SCs are required for the outgrowth-promoting activity of SPARC observed in explants, we next reintroduced purified SCs to the dissociated DRG culture (Fig. 4E, F, H,I). Addition of SCs alone increased neurite length per neuron by more than threefold over minimal NGF conditions (Fig. $4 K$ ). The addition of low concentrations of SPARC (5 $\mathrm{ng} / \mathrm{ml}$ ) further enhanced the increase in neurite length per neuron stimulated by SCs by an additional $12-14 \%(p<0.05)$ (Fig. $4 K$ ).

In looking for alternative pathways that SPARC may modulate to change the ability of Schwann cells to promote neurite outgrowth, we noted that LTBP was also differentially represented in P2 OCM in our ICAT dataset. SPARC has been implicated in regulating TGF $\beta$ responses in a number of other systems (Nunes et al., 1997; Bradshaw and Sage, 2001), and TGF $\beta$ can have a variety of context-dependent effects on the differentiation of Schwann cells (Unsicker and Strelau, 2000). Given that SPARC-treated explants exhibited decreased SC proliferation and yet significantly increased the total neurite outgrowth per cell, we asked whether this action of SPARC might be via a TGF $\beta$-dependent pathway, which could change the differentiation state of explant-derived SCs. To test this possibility, we added a function-blocking antibody against TGF $\beta 1$ (Schiemann et al., 2003) to SPARC-treated explants (Fig. 5B,D), which significantly reduced SPARC-stimulated outgrowth activity but did not result in similar reduction of outgrowth in DRGs grown in high NGF alone (data not shown). Because the outgrowth activity of SPARC appears dependent on TGF $\beta 1$ signaling, TGF $\beta 1$ was added to the outgrowth assay to test whether it could mimic the effect of SPARC. This was not the case, because TGF $\beta 1$ added from 1 to $10 \mathrm{ng} / \mathrm{ml}$ did not increase neurite outgrowth (Fig. $5 E$ ) and, at higher concentrations tested (50 and $100 \mathrm{ng} / \mathrm{ml}$ ), inhibited the ability of explants to adhere consistently to the substrate (data not shown). TGF $\beta 1$ did lower SC density underlying the neurite carpet significantly $\left(96 \pm 26 \mathrm{nuclei} / \mathrm{mm}^{2}\right.$ ) (Fig. $5 C$ ), whereas treatment with anti-TGF $\beta 1$ antibody increased nuclei density $\left(518 \pm 39\right.$ nuclei $/ \mathrm{mm}^{2}$ ) compared with SPARC alone (Fig. $5 A, B$ ). The amount of outgrowth stimulated by each SC in the neurite carpet was also reduced by treatment with anti-TGF $\beta$ antibody, whereas adding TGF $\beta$ increased the ratio above the SPARC-treated group, but with less total outgrowth produced (Fig. $5 E, F$ ). These findings demonstrate that SPARC activity is mediated, in part, through TGF $\beta$ signaling. However, TGF $\beta$ alone cannot substitute for SPARC outgrowth-promoting activity, indicating that SPARC acts upstream of TGF $\beta$ or that both pathways may act cooperatively.

Does SPARC play a role in OEC-mediated spinal cord repair? Multiple tracts, including DRG-derived sensory neurons, sprout after LP-OECs are transplanted into a rat dorsolateral funiculus crush injury (Ramer et al., 2004b; Richter et al., 2005). Trans- 
planted LP-OECs also enhance infiltration of endogenous Schwann cells, alter astrocytic scar formation, stimulate directional angiogenesis, and decrease cavity formation, a secondary loss of tissue normally associated with spinal cord injury. SPARC is highly expressed in SCs, immature astrocytes, and oligodendrocytes in the developing embryo but downregulated to a low level of expression in subpopulations of these glia in the adult (A. J. Vincent and A. J. Roskams, unpublished observations). Given that SPARC appears to be a significant contributor to the bioactivity of OCM-induced outgrowth in vitro and mediates repair in other tissues (Bradshaw and Sage, 2001), we next tested whether LP-OEC-produced SPARC can stimulate outgrowth of specific tracts in vivo or play alternative roles in directing spinal cord repair. GFP-labeled P2 LP-OECs from SPARC-null and strain-matched wildtype mice were transplanted directly into a rat dorsolateral funiculus crush and assessed 28 d later for their efficacy in promoting repair.

Specific subpopulations of spinal and sensory axons normally exhibit robust growth in response to OEC transplantation, including noradrenergic axons originating from the locus ceruleus (RamonCueto et al., 2000; Ramer et al., 2004b; Richter et al., 2005; Lopez-Vales et al., 2006), but why these axons demonstrate enhanced outgrowth is not understood. Sprouting of large- and small-diameter axons into the lesion area (tested with antibodies against $\beta$ III neuron-specific tubulin and heavy-chain neurofilament 200) was not significantly changed in the absence of OEC-produced SPARC (supplemental Fig. S4, available at www. jneurosci.org as supplemental material). Analysis of axon subtypes, however, revealed specific tracts were significantly changed in their sprouting response to LPOECs. There was a 10-fold decrease in the sprouting of ascending substance $\mathrm{P}$-positive sensory axons and a threefold decrease in descending $\mathrm{TH}$-positive axons in SPARC-null LP-OEC-treated animals

(Fig. 6A-F). Other axon subtypes, including CGRP-positive and 5-HT-positive axons, were not significantly different between the two LP-OEC groups (data not shown).

The absence of OEC-produced SPARC did not appear to directly alter the induction of reactive astrogliosis (Fig. 6G,J), the degree of localized angiogenesis (supplemental Fig. S4, available at www.jneurosci.org as supplemental material), the overall size of cavity (data not shown), or the pattern of local laminin-1 deposition at the perilesion boundary (Fig. $6 \mathrm{H}, \mathrm{K}$ ). Although Schwann cell invasion into the lesion still occurred in the absence of OEC-SPARC (supplemental Fig. S4, available at www. jneurosci.org as supplemental material), we noted a marked dif- ference in the arrangement of autofluorescent immune infiltrates that invade the spinal cord lesion site after injury and in the relationship of these cells with transplanted OECs and SCs (Fig. $6 I, L)$. A significant $(45 \pm 6 \% ; p<0.02)$ decrease in the density of ED1-positive macrophages per unit area was recorded within both the lesion and the perilesion boundary of the SPARC-null LP-OEC-treated group compared with WT (Fig. 6I,L). In addition, we noted that a localized upregulation of SPARC occurred in endogenous SCs or astrocytes adjacent to the lesion (Fig. 6G,J), in particular those aligning blood vessels (Fig. $6 \mathrm{H}, \mathrm{K}$ ) around the lesion area. This induction of endogenous glial SPARC expression appeared to be stimulated by the transplanted OECs, be- 

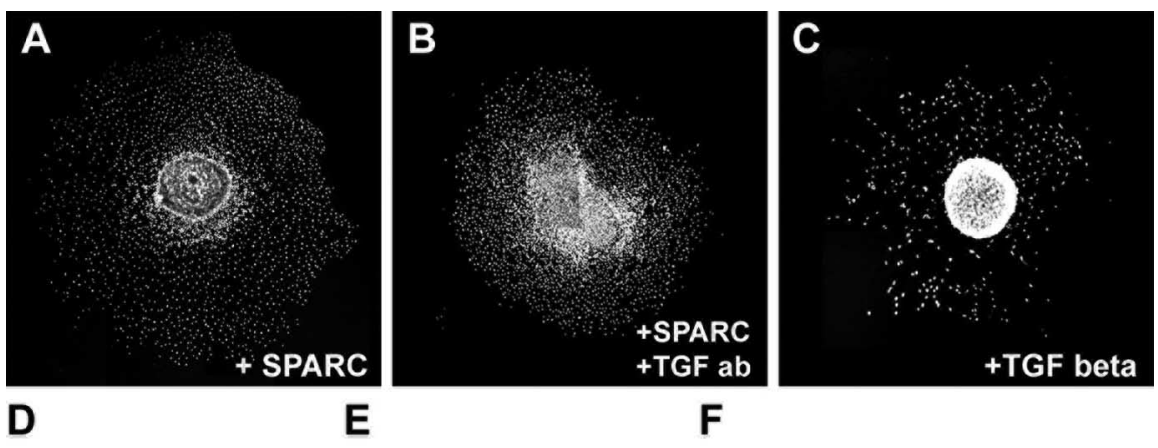

\section{E}
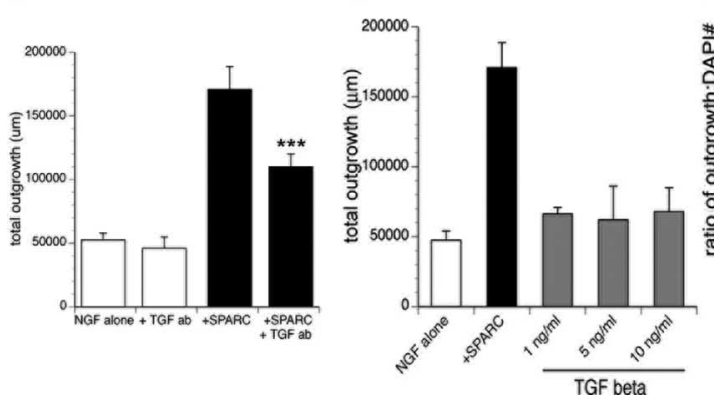

$\mathbf{F}$

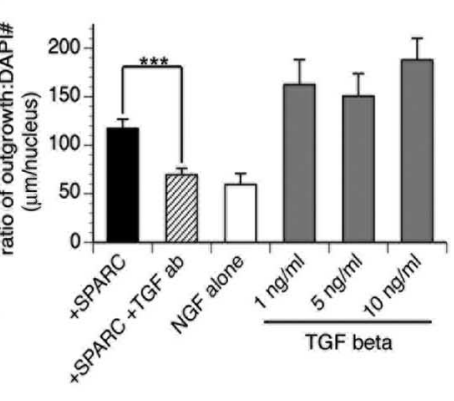

Figure 5. SPARC outgrowth-promoting activity is cooperative with TGF $\beta$. $\boldsymbol{A}-\boldsymbol{C}$, Representative montages of DAPI-positive nuclei in DRG explants grown in NGF supplemented with $5 \mathrm{ng} / \mathrm{ml} \mathrm{rhSPARC}(\boldsymbol{A}), 5 \mathrm{ng} / \mathrm{ml} \mathrm{rhSPARC}$ and TGF $\beta$ function-blocking antibody $(\boldsymbol{B})$, or $5 \mathrm{ng} / \mathrm{ml} \mathrm{TGF} \beta(\boldsymbol{C})$. D, Addition of TGF $\beta$ antibody attenuates the neurite outgrowth activity of SPARC. $\boldsymbol{E}$, Total neurite length quantified for DRG explants grown in NGF alone or supplemented with $5 \mathrm{ng} / \mathrm{ml}$ rhSPARC or various concentrations of TGF $\beta$. Addition of TGF $\beta$ does not result in increased neurite outgrowth. $\boldsymbol{F}$, Ratio of total neurite length per DAPI-positive nucleus for DRG explants grown in NGF alone or supplemented with $5 \mathrm{ng} / \mathrm{ml}$ rhSPARC or SPARC and TGF $\beta$ antibody or TGF $\beta$ at various concentrations. ${ }^{* * *} p<0.0005$. ab, Antibody.

cause it was minimal in "media alone" controls (data not shown). Although the amount of SPARC detected in some astrocytes appears to be significantly lower than OECs (and may be intracellular and not secreted), the induction of endogenous astrocyte- or Schwann cell-produced SPARC immediately adjacent to the lesion site allows us to consider a broader range of SPARC action in SCI repair, beyond the limited boundaries of OEC migration.

\section{Discussion}

Although OEC migration is highly limited within the lesioned spinal cord, a variety of responses distant from the site of transplantation (Li et al., 2003; Ramer et al., 2004b) suggest that OECs may secrete factors that can stimulate more widespread repair after transplantation (Kafitz and Greer, 1999; Chung et al., 2004). The simple observation that OECs significantly lose their potential to promote neurite outgrowth as they age enabled us to use differential proteomics to test which secreted factors may be responsible for this activity. We identified SPARC, a matricellular protein that promotes outgrowth indirectly by converting Schwann cells into an enhanced outgrowth-promoting state by cooperatively signaling with laminin-1 and TGF $\beta$. Our data indicate that OECs may use SPARC to initiate nervous system regeneration/repair and modify how cells within the lesion respond to the ECM environment, to enhance endogenous repair after transplantation into the CNS. These kinds of indirect mechanisms are difficult to uncover but are very important to understand secondary mechanisms stimulated by cell transplantation, as well as in revealing novel pathways that regulate endogenous CNS repair.

By applying an explant system to first test OCM activity, we collectively tested a number of different outgrowth parameters, including total outgrowth coupled with fasciculation and branching patterns, in the presence of endogenous glia. Our data suggest that reported differences in OECstimulated repair can be explained, in part, by (1) different culture conditions used for OECs, (2) differences in the readout of axonal subtypes responding in different assay systems (dissociated versus explant), or (3) differences in the interpretation of analysis approaches within the same assay (supplemental Fig. S1, available at www. jneurosci.org as supplemental material). We thus highlight an important biological and clinical caveat applicable to both OEC and stem cell transplantation experiments: that limited changes in passaging can significantly alter the function of cells in vitro, and subsequently, in vivo.

Here, quantitative proteomics applied to the analysis of secreted factors became a powerful tool for uncovering multifactorial mechanisms in neurobiology. The significant change in biological activity of OECs differing only by passage number allowed us to convert a potentially confounding variable into an interpretable biological assay and provided an ideal platform for ICAT analysis of their secreted factors. In our ICAT dataset, SPARC was highly represented with laminin-1 and LTBP, its cooperative outgrowth regulators. Although not demonstrated previously to promote CNS repair, SPARC expression can also be upregulated by astrocytes during hippocampal sprouting and synaptogenesis (Liu et al., 2005) and may have a potential role in retinal ganglion cell outgrowth (Bampton et al., 2005). Another matricellular protein, thrombospondin, was implicated recently in glia-induced mechanism of synaptogenesis, suggesting that matricellular proteins may have more widespread effects in the glial modulation of nervous system development or remodeling than appreciated previously (Christopherson et al., 2005).

Concomitant with a potential developmental role in regulating axonal outgrowth, SPARC is first found in the nervous system exclusively in glial cells early in embryonic development, in OEC precursors comigrating with ORN axons toward the olfactory bulb (Fig. 2), and in embryonic Schwann cells on the outer margins of developing peripheral and cranial nerves (Vincent and Roskams, unpublished observation). OEC-SPARC expression coincides spatiotemporally with laminin-1 deposition during development and adult ORN regeneration, concurrent with peaks of ORN outgrowth and fasciculation of new ORN axons (Roskams et al., 1996; Struble et al., 2001). Although SPARC is detected in OCM by Western blot in P2/P6 OCM at comparable ratios with ICAT, OECs accumulate intracellular SPARC with successive passages (Fig. 2). With no other recorded secretion deficit, this could reflect a specific decline in SPARC secretion with age. Alternatively, SPARC may instead be actively internalized by senescent LP-OECs, which become flattened and adherent, similar to changes in SPARC secretion reported in aging lens epithelia (Yan et al., 2005).

Collectively, gain- and loss-of-function tests of SPARC demonstrate a dramatic stimulation of neurite outgrowth from DRG 
sensory neurons (Fig. 3). Surprisingly, SPARC-null mice are viable, with distinct alterations in patterns of dermal wound healing (Weaver et al., 2006), but have not been tested for a role for SPARC in CNS repair. Here, OCM from early passage SPARC-null LP-OECs was less effective at promoting total DRG outgrowth than wildtype OCM but still significantly stimulated neurite length (supplemental Fig. S3, available at www.jneurosci.org as supplemental material). These data concur with function-blocking experiments and indicate that the increased outgrowth attributed to SPARC can primarily be attributed to an increase in overall neurite density, not length (Figs. 1, 3), and that other OECsecreted factors can stimulate neurite extension, the activity of which were potentially masked by the dominant presence of SPARC in OCM. In the absence of SPARC, the compensatory induction of other factors, such as SPARC-like 1, a member of the SPARC family expressed in the developing CNS (Mothe and Brown, 2001), could occur but does not compensate for the outgrowth effect stimulated by SPARC in our assay. The increase in neurite density is also not attributable to increased survival, because we did not detect greater loss of DRG neurons grown in OCM from SPARC nulls, nor did MAPK inhibition (required for NGF-dependent neurite outgrowth) (Sjogreen et al., 2000) change the profile of SPARC-stimulated outgrowth (Fig. 3). These results indicate that our baseline conditions support neuronal survival and that SPARC-mediated outgrowth occurs via an MAPK-independent pathway.

OECs have been suggested to enhance the ability of SCs to both promote axonal regeneration and remyelinate damaged axons, but there is no established mechanism for this (Imaizumi et al., 2000; Bunge and Pearse, 2003; Dunning et al., 2004). SPARC-treated explants had fewer mitotic SCs but increased neurite outgrowth and SC-neurite association, suggesting that SCs, in the presence of SPARC, were promoting outgrowth more effectively (Figs. 2-4). Removing SCs from the explant assay drastically reduced SPARC-induced outgrowth, and sprouting in pure DRG neurons was unaffected by SPARC, indicating that SCs may be required to potentiate SPARC action. To confirm this, reintroduction of SCs with SPARC once again restored the DRG outgrowth response to SPARC. Axonal sprouting in regions of SC axonal contact in the OECtransplanted spinal cord is again a consistent finding, across several groups for which we now have a potential explanation (Bunge, 2002; Boyd et al., 2004). Consistent with an interdependence between SPARC and laminin-1 beyond the nervous system (Rempel et al., 2001; Sweetwyne et al., 2004), SPARC had a reduced ability to stimulate outgrowth in the absence of exogenous laminin-1 (Fig. 4). SPARC can also stimulate TGF $\beta$ expression (Reed et al., 1994; Francki et al., 1999) and potentiate its ligandreceptor signaling (Schiemann et al., 2003; Francki et al., 2004). TGF $\beta$ affects SC proliferation in a context-dependent manner, acting as a strong mitogen in the absence of axonal contact (Eccleston et al., 1989) and inhibiting proliferation in coculture with neurons (Guenard et al., 1995). Changes in SPARC-induced SC proliferation and resulting outgrowth stimulation were blocked when the function of TGF $\beta 1$ was blocked and were not mimicked by adding exogenous TGF $\beta$. Although this could be confounded by the fact that SCs can synthesize SPARC (Bampton et al., 2005), they express SPARC at significantly lower levels than OECs, and the majority of their SPARC appears to be intracellular and not 
secreted. Any minimal SC-derived SPARC clearly has no effect on assay outgrowth promotion, as evidenced by significantly greater outgrowth in the presence of OCM/SPARC versus NGF alone, and the additional enhancement of outgrowth when SCs pretreated with SPARC are seeded onto dissociated DRG neurons. Thus, SPARC appears to potentiate the activity of laminin-1 and TGF $\beta$ and act as a rheostat for SC differentiation, increasing the likelihood that they will shift from a mitotic state into one of direct contact and axonal outgrowth.

Having revealed a new mechanism whereby SPARC attenuates SC-neuronal interactions and outgrowth promotion in vitro, we next tested whether SPARC action may influence spinal cord repair by transplanting OECs derived from SPARC-null mice. The lack of OEC-derived SPARC revealed two distinct subpopulations, spinal (TH-positive) and sensory (substance P-positive) neurons, whose outgrowth was exquisitely sensitive to OECderived SPARC in vivo. In addition, endogenous astrocytes and Schwann cells around the lesion site upregulated SPARC expression after OEC transplant but to levels substantially less than those detected in transplanted OECs. This gradient of induced endogenous glial SPARC expression could thus propagate SPARC-mediated repair to points distant from the lesion, in which OECs are not found. Schwann cells and astrocytes are normally segregated to opposite sides of the laminin-rich basal lamina of the PNS-CNS boundary, yet transplanted OECs help to reestablish a laminin-rich perilesion boundary in the CNS within which SCs and astrocyte freely interact, thus facilitating axon entry to the lesion site (Richter et al., 2005). Intracellular SPARC can regulate cell morphology and motility via a direct interaction with integrin-linked kinase, which has been implicated in the autoregulation of glial laminin production and migration in the CNS (Mills et al., 2006). OEC-produced SPARC at the lesion core could also regulate local laminin-1 production, glial migration, and axonal responsiveness and shift the normally inhibitory ECM environment of the glial scar into one that permits the endogenous astrocytes and Schwann cells to interact and collectively enhance repair (Barker et al., 2005).

We demonstrated previously differential stimulation of angiogenesis at the perilesion boundary (Richter et al., 2005), a phenomenon that could be enhanced by secreted SPARC after its cleavage by matrix metalloprotease 3 (Sage et al., 2003), an enzyme rapidly induced in reactive CNS astrocytes. A final unexpected response that is diminished in the absence of OECproduced SPARC is the pattern of macrophage recruitment after lesion and cell transplantation. Wild-type OECs expressing SPARC enhance the inflammatory response at the lesion site over SPARC-null OECs, a process that is hotly debated as having a reparative (Schwartz, 2003), as opposed to a potentially degenerative, role in CNS repair (Schnell et al., 1999). A role in changing the local immune response within the CNS has not been previously mechanistically established for SPARC, and the direct or indirect effects of this change could be highly significant in harnessing the endogenous power of the immune system to modulate the local repair environment.

Here, we show for the first time that SPARC, a matricellular protein implicated in wound repair and angiogenesis systemically, can contribute significantly to a collection of mechanisms at the core of endogenous CNS repair. SPARC, secreted by OECs, can enhance the outgrowth-promoting phenotype of Schwann cells, evoking enhanced outgrowth of substance P-positive fibers and intraspinal noradrenergic fiber sprouting in vivo. OECproduced SPARC can stimulate the upregulation of endogenous glial SPARC expression at the laminin-rich perilesion boundary and concurrently alter the local immune response to transplanted cells. It thus appears that the local secretion of OEC-derived SPARC initiates a series of mechanisms that can shift the hostile lesion site environment into one supporting significant aspects of endogenous CNS repair.

\section{References}

Au E, Roskams AJ (2002) Culturing olfactory ensheathing glia from the mouse olfactory epithelium. Methods Mol Biol 198:49-54.

Au E, Roskams AJ (2003) Olfactory ensheathing cells of the lamina propria in vivo and in vitro. Glia 41:224-236.

Bampton ET, Ma CH, Tolkovsky AM, Taylor JS (2005) Osteonectin is a Schwann cell-secreted factor that promotes retinal ganglion cell survival and process outgrowth. Eur J Neurosci 21:2611-2623.

Banker G, Goslin K, eds (1998) Culturing nerve cells, Ed 2. Cambridge, MA: MIT.

Barker TH, Baneyx G, Cardo-Vila M, Workman GA, Weaver M, Menon PM, Dedhar S, Rempel SA, Arap W, Pasqualini R, Vogel V, Sage EH (2005) SPARC regulates extracellular matrix organization through its modulation of integrin-linked kinase activity. J Biol Chem 280:36483-36493.

Boyd JG, Lee J, Skihar V, Doucette R, Kawaja MD (2004) LacZ-expressing olfactory ensheathing cells do not associate with myelinated axons after implantation into the compressed spinal cord. Proc Natl Acad Sci USA 101:2162-2166.

Bradshaw AD, Sage EH (2001) SPARC, a matricellular protein that functions in cellular differentiation and tissue response to injury. J Clin Invest 107:1049-1054.

Bradshaw AD, Bassuk JA, Francki A, Sage EH (2000) Expression and purification of recombinant human SPARC produced by baculovirus. Mol Cell Biol Res Commun 3:345-351.

Bradshaw AD, Puolakkainen P, Dasgupta J, Davidson JM, Wight TN, Helene Sage E (2003) SPARC-null mice display abnormalities in the dermis characterized by decreased collagen fibril diameter and reduced tensile strength. J Invest Dermatol 120:949-955.

Brekken RA, Sage EH (2001) SPARC, a matricellular protein: at the crossroads of cell-matrix communication. Matrix Biol 19:816-827.

Bunge MB (2002) Bridging the transected or contused adult rat spinal cord with Schwann cell and olfactory ensheathing glia transplants. Prog Brain Res 137:275-282.

Bunge MB, Pearse DD (2003) Transplantation strategies to promote repair of the injured spinal cord. J Rehabil Res Dev 40:55-62.

Cagney G, Amiri S, Premawaradena T, Lindo M, Emili A (2003) In silico proteome analysis to facilitate proteomics experiments using mass spectrometry. Proteome Sci 1:5.

Chernousov MA, Scherer SS, Stahl RC, Carey DJ (1999) p200, a collagen secreted by Schwann cells, is expressed in developing nerves and in adult nerves following axotomy. J Neurosci Res 56:284-294.

Chernousov MA, Rothblum K, Tyler WA, Stahl RC, Carey DJ (2000) Schwann cells synthesize type V collagen that contains a novel alpha 4 chain. Molecular cloning, biochemical characterization, and high affinity heparin binding of alpha $4(\mathrm{~V})$ collagen. J Biol Chem 275:28208-28215.

Christopherson KS, Ullian EM, Stokes CC, Mullowney CE, Hell JW, Agah A, Lawler J, Mosher DF, Bornstein P, Barres BA (2005) Thrombospondins are astrocyte-secreted proteins that promote CNS synaptogenesis. Cell 120:421-433.

Chuah MI, Au C (1994) Olfactory cell cultures on ensheathing cell monolayers. Chemical Senses 19:25-34.

Chung RS, Woodhouse A, Fung S, Dickson TC, West AK, Vickers JC, Chuah MI (2004) Olfactory ensheathing cells promote neurite sprouting of injured axons in vitro by direct cellular contact and secretion of soluble factors. Cell Mol Life Sci 61:1238-1245.

Coloma MJ, Hastings A, Wims LA, Morrison SL (1992) Novel vectors for the expression of antibody molecules using variable regions generated by polymerase chain reaction. J Immunol Methods 152:89-104.

Cowan CM, Roskams AJ (2004) Caspase-3 and caspase-9 mediate developmental apoptosis in the mouse olfactory system. J Comp Neurol 474:136-148.

Cowan CM, Thai J, Krajewski S, Reed JC, Nicholson DW, Kaufmann SH, Roskams AJ (2001) Caspases 3 and 9 send a pro-apoptotic signal from synapse to cell body in olfactory receptor neurons. J Neurosci 21:7099-7109. 
Doucette R (1990) Glial influences on axonal growth in the primary olfactory system. Glia 3:433-449.

Dunning MD, Lakatos A, Loizou L, Kettunen M, ffrench-Constant C, Brindle KM, Franklin RJ (2004) Superparamagnetic iron oxide-labeled Schwann cells and olfactory ensheathing cells can be traced in vivo by magnetic resonance imaging and retain functional properties after transplantation into the CNS. J Neurosci 24:9799-9810.

Eccleston PA, Jessen KR, Mirsky R (1989) Transforming growth factor-beta and gamma-interferon have dual effects on growth of peripheral glia. J Neurosci Res 24:524-530.

Fairless R, Barnett SC (2005) Olfactory ensheathing cells: their role in central nervous system repair. Int J Biochem Cell Biol 37:693-699.

Farbman AI (1990) Olfactory neurogenesis: genetic or environmental controls? Trends Neurosci 13:362-365.

Fawcett JW, Asher RA (1999) The glial scar and central nervous system repair. Brain Res Bull 49:377-391.

Francki A, Bradshaw AD, Bassuk JA, Howe CC, Couser WG, Sage EH (1999) SPARC regulates the expression of collagen type I and transforming growth factor-betal in mesangial cells. J Biol Chem 274:32145-32152.

Francki A, McClure TD, Brekken RA, Motamed K, Murri C, Wang T, Sage EH (2004) SPARC regulates TGF-beta1-dependent signaling in primary glomerular mesangial cells. J Cell Biochem 91:915-925.

Franklin RJ, Gilson JM, Franceschini IA, Barnett SC (1996) Schwann celllike myelination following transplantation of an olfactory bulbensheathing cell line into areas of demyelination in the adult CNS. Glia 17:217-224.

Graziadei PP, Monti Graziadei AG (1983) Regeneration in the olfactory system of vertebrates. Am J Otolaryngol 4:228-233.

Graziadei PP, Levine RR, Monti Graziadei GA (1979) Plasticity of connections of the olfactory sensory neuron: regeneration into the forebrain following bulbectomy in the neonatal mouse. Neuroscience 4:713-727.

Guenard V, Rosenbaum T, Gwynn LA, Doetschman T, Ratner N, Wood PM (1995) Effect of transforming growth factor-beta 1 and -beta 2 on Schwann cell proliferation on neurites. Glia 13:309-318.

Gygi SP, Rist B, Gerber SA, Turecek F, Gelb MH, Aebersold R (1999) Quantitative analysis of complex protein mixtures using isotope-coded affinity tags. Nat Biotechnol 17:994-999.

Hawley TS, Telford WG, Hawley RG (2001) "Rainbow" reporters for multispectral marking and lineage analysis of hematopoietic stem cells. Stem Cells 19:118-124.

Huang H, Chen L, Wang H, Xiu B, Li B, Wang R, Zhang J, Zhang F, Gu Z, Li Y, Song Y, Hao W, Pang S, Sun J (2003) Influence of patients' age on functional recovery after transplantation of olfactory ensheathing cells into injured spinal cord injury. Chin Med J (Engl) 116:1488-1491.

Imaizumi T, Lankford KL, Kocsis JD (2000) Transplantation of olfactory ensheathing cells or Schwann cells restores rapid and secure conduction across the transected spinal cord. Brain Res 854:70-78.

Kafitz KW, Greer CA (1999) Olfactory ensheathing cells promote neurite extension from embryonic olfactory receptor cells in vitro. Glia 25:99-110

Li Y, Field PM, Raisman G (1997) Repair of adult rat corticospinal tract by transplants of olfactory ensheathing cells. Science 277:2000-2002.

Li Y, Decherchi P, Raisman G (2003) Transplantation of olfactory ensheathing cells into spinal cord lesions restores breathing and climbing. J Neurosci 23:727-731.

Lipson AC, Widenfalk J, Lindqvist E, Ebendal T, Olson L (2003) Neurotrophic properties of olfactory ensheathing glia. Exp Neurol 180:167-171.

Liu X, Ying G, Wang W, Dong J, Wang Y, Ni Z, Zhou C (2005) Entorhinal deafferentation induces upregulation of SPARC in the mouse hippocampus. Brain Res Mol Brain Res 141:58-65.

Lopez-Vales R, Fores J, Verdu E, Navarro X (2006) Acute and delayed transplantation of olfactory ensheathing cells promote partial recovery after complete transection of the spinal cord. Neurobiol Dis 21:57-68.

Mackay-Sim A (2005) Olfactory ensheathing cells and spinal cord repair. Keio J Med 54:8-14.

Miller AD, Buttimore C (1986) Redesign of retrovirus packaging cell lines to avoid recombination leading to helper virus production. Mol Cell Biol 6:2895-2902.

Mills J, Niewmierzycka A, Oloumi A, Rico B, St-Arnaud R, Mackenzie IR, Mawji NM, Wilson J, Reichardt LF, Dedhar S (2006) Critical role of integrin-linked kinase in granule cell precursor proliferation and cerebellar development. J Neurosci 26:830-840.

Mothe AJ, Brown IR (2001) Differential mRNA expression of the related extracellular matrix glycoproteins SC1 and SPARC in the rat embryonic nervous system and skeletal structure. Brain Res 892:27-41.

Mu X, Silos-Santiago I, Carroll SL, Snider WD (1993) Neurotrophin receptor genes are expressed in distinct patterns in developing dorsal root ganglia. J Neurosci 13:4029-4041.

Norose K, Clark JI, Syed NA, Basu A, Heber-Katz E, Sage EH, Howe CC (1998) SPARC deficiency leads to early-onset cataractogenesis. Invest Ophthalmol Vis Sci 39:2674-2680.

Nunes I, Gleizes PE, Metz CN, Rifkin DB (1997) Latent transforming growth factor-beta binding protein domains involved in activation and transglutaminase-dependent cross-linking of latent transforming growth factor-beta. J Cell Biol 136:1151-1163.

Raines EW, Lane TF, Iruela-Arispe ML, Ross R, Sage EH (1992) The extracellular glycoprotein SPARC interacts with platelet-derived growth factor (PDGF)-AB and -BB and inhibits the binding of PDGF to its receptors. Proc Natl Acad Sci USA 89:1281-1285.

Ramer LM, Richter MW, Roskams AJ, Tetzlaff W, Ramer MS (2004a) Peripherally-derived olfactory ensheathing cells do not promote primary afferent regeneration following dorsal root injury. Glia 47:189-206.

Ramer LM, Au E, Richter MW, Liu J, Tetzlaff W, Roskams AJ (2004b) Peripheral olfactory ensheathing cells reduce scar and cavity formation and promote regeneration after spinal cord injury. J Comp Neurol 473:1-15.

Ramon-Cueto A, Avila J (1998) Olfactory ensheathing glia: properties and function. Brain Res Bull 46:175-187.

Ramon-Cueto A, Nieto-Sampedro M (1994) Regeneration into the spinal cord of transected dorsal root axons is promoted by ensheathing glia transplants. Exp Neurol 127:232-244.

Ramon-Cueto A, Plant GW, Avila J, Bunge MB (1998) Long-distance axonal regeneration in the transected adult rat spinal cord is promoted by olfactory ensheathing glia transplants. J Neurosci 18:3803-3815.

Ramon-Cueto A, Cordero MI, Santos-Benito FF, Avila J (2000) Functional recovery of paraplegic rats and motor axon regeneration in their spinal cords by olfactory ensheathing glia. Neuron 25:425-435.

Reed MJ, Vernon RB, Abrass IB, Sage EH (1994) TGF-beta 1 induces the expression of type I collagen and SPARC, and enhances contraction of collagen gels, by fibroblasts from young and aged donors. J Cell Physiol 158:169-179.

Rempel SA, Golembieski WA, Fisher JL, Maile M, Nakeff A (2001) SPARC modulates cell growth, attachment and migration of U87 glioma cells on brain extracellular matrix proteins. J Neurooncol 53:149-160.

Richter MW, Fletcher PA, Liu J, Tetzlaff W, Roskams AJ (2005) Lamina propria and olfactory bulb ensheathing cells exhibit differential integration and migration and promote differential axon sprouting in the lesioned spinal cord. J Neurosci 25:10700-10711.

Riddell JS, Enriquez-Denton M, Toft A, Fairless R, Barnett SC (2004) Olfactory ensheathing cell grafts have minimal influence on regeneration at the dorsal root entry zone following rhizotomy. Glia 47:150-167.

Roskams AJ, Bethel MA, Hurt KJ, Ronnett GV (1996) Sequential expression of Trks A, B, and C in the regenerating olfactory neuroepithelium. J Neurosci 16:1294-1307.

Ruit KG, Elliott JL, Osborne PA, Yan Q, Snider WD (1992) Selective dependence of mammalian dorsal root ganglion neurons on nerve growth factor during embryonic development. Neuron 8:573-587.

Sage EH, Reed M, Funk SE, Truong T, Steadele M, Puolakkainen P, Maurice DH, Bassuk JA (2003) Cleavage of the matricellular protein SPARC by matrix metalloproteinase 3 produces polypeptides that influence angiogenesis. J Biol Chem 278:37849-37857.

Sage H, Vernon RB, Decker J, Funk S, Iruela-Arispe ML (1989) Distribution of the calcium-binding protein SPARC in tissues of embryonic and adult mice. J Histochem Cytochem 37:819-829.

Santos-Benito FF, Ramon-Cueto A (2003) Olfactory ensheathing glia transplantation: a therapy to promote repair in the mammalian central nervous system. Anat Rec 271B:77-85.

Schiemann BJ, Neil JR, Schiemann WP (2003) SPARC inhibits epithelial cell proliferation in part through stimulation of the transforming growth factor-beta-signaling system. Mol Biol Cell 14:3977-3988.

Schnell L, Fearn S, Klassen H, Schwab ME, Perry VH (1999) Acute inflam- 
matory responses to mechanical lesions in the CNS: differences between brain and spinal cord. Eur J Neurosci 11:3648-3658.

Schwartz M (2003) Macrophages and microglia in central nervous system injury: are they helpful or harmful? J Cereb Blood Flow Metab 23:385-394.

Sjogreen B, Wiklund P, Ekstrom PA (2000) Mitogen activated protein kinase inhibition by PD98059 blocks nerve growth factor stimulated axonal outgrowth from adult mouse dorsal root ganglia in vitro. Neuroscience 100:407-416.

Sonigra RJ, Kandiah SS, Wigley CB (1996) Spontaneous immortalisation of ensheathing cells from adult rat olfactory nerve. Glia 16:247-256.

Struble RG, Beckman SL, Fesser E, Nathan BP (2001) Volumetric and horseradish peroxidase tracing analysis of rat olfactory bulb following reversible olfactory nerve lesions. Chem Senses 26:971-981.

Sweetwyne MT, Brekken RA, Workman G, Bradshaw AD, Carbon J, Siadak AW, Murri C, Sage EH (2004) Functional analysis of the matricellular protein SPARC with novel monoclonal antibodies. J Histochem Cytochem 52:723-733.

Unsicker K, Strelau J (2000) Functions of transforming growth factor-beta isoforms in the nervous system. Cues based on localization and experimental in vitro and in vivo evidence. Eur J Biochem 267:6972-6975.

Von Haller PD, Yi E, Donohoe S, Vaughn K, Keller A, Nesvizhskii AI, Eng J, Li XJ, Goodlett DR, Aebersold R, Watts JD (2003) The application of new software tools to quantitative protein profiling via isotope-coded affinity tag (ICAT) and tandem mass spectrometry. I. Statistically annotated datasets for peptide sequences and proteins identified via the application of ICAT and tandem mass spectrometry to proteins copurifying with $\mathrm{T}$ cell lipid rafts. Mol Cell Proteomics 2:426-427.

Wang H, Fertala A, Ratner BD, Sage EH, Jiang S (2005) Identifying the SPARC binding sites on collagen I and procollagen I by atomic force microscopy. Anal Chem 77:6765-6771.

Weaver MS, Sage EH, Yan Q (2006) Absence of SPARC in lens epithelial cells results in altered adhesion and extracellular matrix production in vitro. J Cell Biochem 97:423-432.

Yan Q, Weaver M, Perdue N, Sage EH (2005) Matricellular protein SPARC is translocated to the nuclei of immortalized murine lens epithelial cells. J Cell Physiol 203:286-294. 